\title{
Influence of Herbal Mouthwashes and Chlorhexidine Mouthwash on the Physical Characteristics of Orthodontic Acrylic Resin
}

\author{
Farzaneh Golfeshan, ${ }^{1}$ Shabnam Ajami, ${ }^{1}$ Yasaman Khalvandi, ${ }^{2}$ Seyed Ali Mosaddad, ${ }^{3}$ Haniye Nematollahi ${ }^{2}$ \\ ${ }^{1}$ Orthodontics Research Center, Department of Orthodontics, School of Dentistry, Shiraz University of Medical \\ Sciences, Shiraz; ${ }^{2}$ School of Dentistry, Shiraz University of Medical Sciences, Shiraz; ${ }^{3}$ School of Dentistry, Shiraz \\ University of Medical Sciences, Shiraz, Iran
}

\begin{abstract}
The present study, intended to compare the effects of immersion in herbal mouthwashes and the Chlorhexidine mouthwash on orthodontic acrylic resin, specifically with regard to alterations in its hardness, roughness and color. Seventy-two specimens of Orthodontic self-cured acrylic resin were used for the experiments. After preparation, specimens were placed in three types of mouthwash including Chlorhexidine $0.2 \%(\mathrm{CHX})$, Persica and Matrica. The changes in microhardness $(\Delta \mathrm{KNH})$, Surface roughness $(\Delta \mathrm{Ra})$ and color $(\Delta \mathrm{E})$ were evaluated prior to and following the immersion in mouthwashes. In order to analyze the data, we made use of SPSS version 22. One-Way ANOVA test was used to find the differences between groups. The Tukey test was conducted in the final stage. It was revealed that acrylic resins had lower microhardness when 12 hours after immersion had taken place. There were significant differences after $12 \mathrm{~h}, 24 \mathrm{~h}$ and 7 days between the groups in the softening of acrylic resins. The reduc-
\end{abstract}

Correspondence: Seyed Ali Mosaddad, School of Dentistry, Shiraz

University of Medical Sciences, Shiraz, Iran

Tel.: +989175827063;

E-mail: mosaddad.sa@gmail.com

Key words: Orthodontic appliances; Mouthwashes; Hardness; Acrylic resins.

Acknowledgments: The authors thank the vice-chancellery of Shiraz University of Medical Sciences for supporting the research (Grant\# 98-01-37-19703). Also, the authors thank Dr. Vosough from the Dental Research Development Center for the statistical analysis.

Conflict of Interest: The authors declare no potential conflict of interests.

Received for publication: 6 March 2020.

Accepted for publication: 28 April 2020.

${ }^{\circ}$ Copyright: the Author(s), 2020

Licensee PAGEPress, Italy

Journal of Biological Research 2020; 93:8949

doi:10.4081/jbr.2020.8949

This article is distributed under the terms of the Creative Commons Attribution Noncommercial License (by-nc 4.0) which permits any noncommercial use, distribution, and reproduction in any medium, provided the original author(s) and source are credited. tion in microhardness of acrylic resin with herbal mouthwashes in the three-time intervals was higher than $\mathrm{CHX}$. With regard to increasing surface roughness, the disparity between herbal mouthwashes was insignificant. However herbal mouthwashes significantly increased the value of roughness more than CHX. Changes in color were significantly higher in all mouthwashes. Herbal mouthwashes caused more color variation than CHX. The color, roughness and hardness of acrylic resin undergo changes as a result of being immersed in the mouthwashes. However, the effect of herbal mouthwashes was more than that of $\mathrm{CHX}$.

\section{Introduction}

Orthodontic removable appliances have diverse uses in contemporary orthodontic treatment. ${ }^{1}$ They can be used in myofunctional therapies, small tooth movements or the retention of orthodontic treatments. ${ }^{2}$ The different components of removable appliances such as the retentive sites of clasp, springs and especially acrylic base plates are suitable environments for microbial colonization because of their subsurface porosity. ${ }^{3,4}$ It was reported that gingivitis, halitosis and dental caries is more common among children in treatment with removable orthodontic appliances. ${ }^{5}$ Therefore, good hygiene of orthodontic removable appliances is necessary to reduce these side effects ${ }^{6}$ because biofilms on tooth surface may lead to dental caries, and supra- and subgingival plaques along and below the gingival crevice may cause periodontal disorders.?

The studies showed that the use of water alone or the brushing of removable appliances cannot completely remove microorganism biofilms from retentive sites and the microporosity of removable appliance. ${ }^{8}$ Today, a combination of mechanical and chemical methods is routinely recommended. ${ }^{9}$ The chemical solutions which are used for the disinfection of removable appliances should not have a negative impact on the physical properties of the acrylic base plate and the other components of these appliances. ${ }^{10}$ For instance, immersion in some chemical solutions may cause the plasticization of polymer chains in acrylic base plates, leading to material degradation due to the increase in water sorption and solubility. ${ }^{11}$ Chlorhexidine (CHX) is one of the most commonly used chemical solutions for biofilm control in this regard. However, it was reported that $\mathrm{CHX}$ negatively affects some properties of acrylic resin such as transverse strength, ${ }^{12}$ color stability, ${ }^{13}$ roughness and hardness. ${ }^{14}$

Currently, due to some undesirable side effects reported from CHX consumption, the tendency to use herbal solutions as an aid for the disinfection of removable appliances has been increased. ${ }^{15-}$ 
17 Persica is an herbal solution, containing an extract of Salvadora persica (S. persica). Benzyl Isothiocyanate is the major component of this herbal extract that prevents acid from being produced and Streptococcus mutans from growing. Besides antivirals and antifungals activity of this herbal extract have been reported. ${ }^{16-19}$

Matrica is another herbal solution that contains chamomile extract. Chamomile is a flower with the scientific name Matricaria chamomilla from the Compositae Family. ${ }^{20}$ The reason for the heightened interest in the use of this herbal solution is that chamomile has anticancer, antifungal, anti-bacterial and antiinflammatory characteristics, which make it particularly effective against Candida albicans and the herpes virus. ${ }^{21,22}$

At present (or to date) the desire to use herbal mouthwashes as a disinfectant is increasing. Studies have shown that some herbal mouthwashes, especially those containing chamomile can have far more antifungal effects than $\mathrm{CHX}$ with fewer negative side effects. ${ }^{23,24}$ An ideal disinfectant solution in addition to have good antibacterial and antifungal effects must not have destructive effects on the physical and mechanical properties of orthodontic acrylic resins. Since no studies have been performed to compare the effect of herbal mouthwashes with chemical ones on the physical and mechanical properties of orthodontic acrylic resins, the present study was designed. In this research, our intention was to carry out a comparison between and assessment on the way CHX, Persica, and Matrica influence acrylic resin in terms of its physical characteristics. These three types of mouthwash were chosen because CHX is the most common chemical mouthwash and Matrica and Persica are the most ones in the herbal mouthwashes with antifungal and antibacterial effects. It was held as the null hypothesis that herbal solutions do not alter the physical characteristics of acrylic resin as much as CHX.

\section{Materials and Methods}

This in vitro double blinded study was approved ethically (IR.SUMS.REC.1398.063). Chlorhexidine digluconate $0.2 \%$ (Behsa Co., Iran) and two other types of herbal mouthwashes including Persica 10\% (Poursina Co., Iran) and Matrica 10\% (Barij Essence pharmaceutical Co., Iran) were used in this study. As the mean wearing time of orthodontic appliances is 13.4 $( \pm 10.3)$ months,${ }^{25}$ in the present study the microhardness, roughness and colorimetric analysis were checked after $12 \mathrm{~h}, 24 \mathrm{~h}$ and 7 days for each mouthwash. These time intervals were established to replicate, and even extrapolate, situations in orthodontic patients' home disinfection practice. Before the resin samples were submerged in the solutions, the $\mathrm{pH}$ of the mouthwashes was measured. For this measurement, a digital $\mathrm{pH}$ meter was used ${ }^{26}$, 27 ( $\mathrm{pH}$ 21, Hanna Instruments Inc., Woonsocket, RI, USA) at room temperature.

\section{Acrylic resin specimens}

Seventy-two Acrylic resin specimens (10 mm diameter and 2.5 $\mathrm{mm}$ thickness) were prepared using cold cure acrylic resin (Ortho Clas ${ }^{\circledR}$; Acropars). To produce a smooth surface, each coin was polished (Figure 1). Forty-five specimens were randomly divided into 9 groups $(n=5)$ per time interval and mouthwash for microhardness and roughness tests. The remaining 27 were used to create 9 other groups $(n=3)$ for each time interval and mouthwash for color analysis. After the initial measurements, the acrylic resin was immersed in $30 \mathrm{ml}$ of mouthwash for $12 \mathrm{~h}, 24 \mathrm{~h}$ and 7 days. After mouthwash immersion, the specimens were washed with distilled water for $10 \mathrm{~s}$ and dried with compressed air for 1 minute. Then, the second measurement was done as described below.

\section{Microhardness Test}

A hardness tester machine (SCTMC Company, MHV_1000Z model, Chinese) was used to determine the surface Knoop microhardness (KHN) of specimens at the beginning and at the end of the experiment. A $25 \mathrm{~g}$ load was applied to surface of the specimens for 10 seconds in order to create 3 indentations. The value of $\mathrm{KHN}$ was measured according to the following formula:

$$
\mathrm{KHN}=\left[(14228 \mathrm{c}) /\left(\mathrm{d}^{2}\right)\right]
$$

Where: $\mathrm{c}=$ applied load in $\mathrm{g} ; \mathrm{d}=$ length of the longest indentation diagonal in $\mathrm{mm} ; 14228=$ constant number.

The KHN value of the specimen was determined by calculating the mean value of the three indentations. By comparing the Knoop microhardness at the beginning and the end, and by calculating the percentage of difference between the two (KHNF $\mathrm{KHNI})$, the softening of acrylic resin $(\triangle \mathrm{KHN})$ was determined (Figure 2).

\section{Roughness}

In order to determine the mean surface roughness of each specimen a roughness surface analyzer was used (COMPANY TESA, RUGOSOR Model, Switzerland). This device benefited from a metal tip that could move up and down at an accuracy of \pm 0.01 Micrometer $(\mu \mathrm{m})$. Furthermore, it was capable of precisely probing and recording $3 \mathrm{~mm}$ segments of each group in $15 \mathrm{sec}$ onds. The tip moved up and down upwards and downwards. This irregular pattern was plotted against the profile of the surface

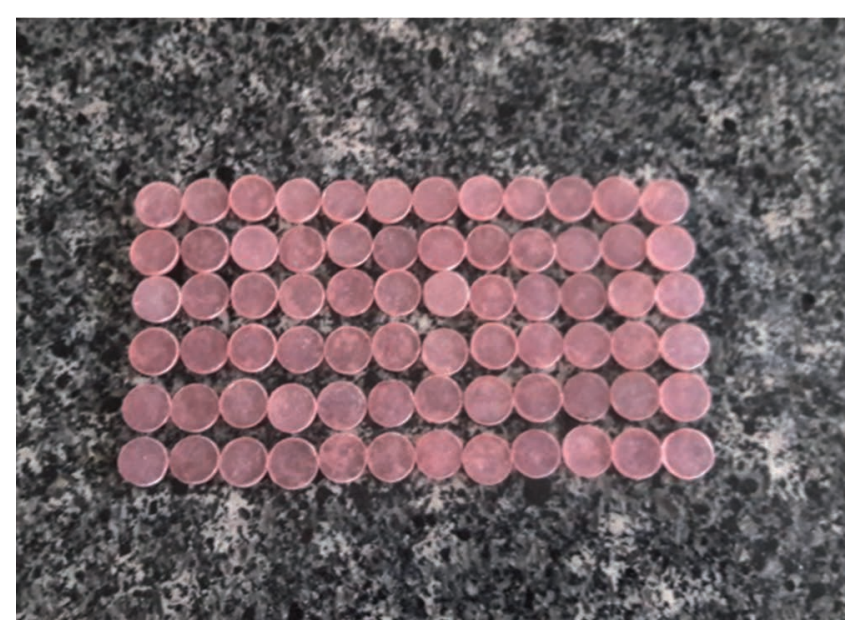

Figure 1. Preparation of acrylic resin specimens. 
explored. In every scan, a length of $3 \mathrm{~mm}$ was analyzed. Three profilometric scans were performed at different parts of each wire section. The equipment automatically determined the profilometric mean roughness from the surface of each specimen (Figure 3A)

\section{Colorimetric Analysis}

Color changes were measured using a spectrophotometer (VITA Company, Easy shade V Model, Germany Figure 3B). Color changes were calculated according to the International Commission on Illumination. ${ }^{20}$ The CIE Lab system allows color perception in three-dimensional space through a wavelength versus refraction index. Color evaluation took place under the following conditions: $\mathrm{L}^{*} \mathrm{a} \mathrm{b}^{*}$ coordinates were calculated in daylight conditions (D65 CIE illuminant) from an observation angle of 10 degrees. In these calculations, "L" stands for luminosity on a scale from 0 to 100; "a" stands for the amount of red and green; and "b" stands for the amount of yellow and blue. In order to determine color changes from one point to another, the CIE Lab system utilizes the formula below:

$$
\mathrm{E}=\sqrt{\left[(\Delta \mathrm{L})^{2}+(\Delta \mathrm{a})^{2}+(\Delta \mathrm{b})^{2}\right]}
$$

\section{Statistical Analysis}

Data analysis was conducted with SPSS version 22. In order to determine discrepancies between the two groups, One-Way ANOVA test was utilized. In the final stage, the Tukey test was carried out. While analyzing the data, values greater than 0.05 were considered significant.
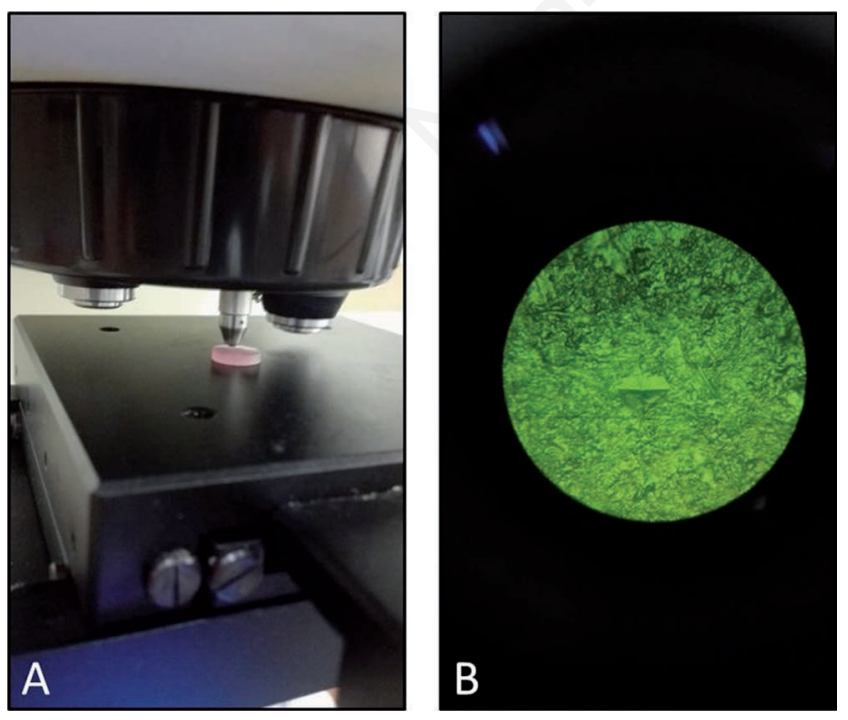

Figure 2. The microhardness tester machine (A) and the view of acrylic resin under microhardness tester machine after immersion in CHX for $12 \mathrm{~h} \mathrm{(B)}$.

\section{Results}

\section{pH of the Mouthwashes}

The values of $\mathrm{pH}$ solutions varied from a minimum of $4.22 \pm 0.03$ to a maximum of $7.3 \pm 0.05$, which indicated that the differences among groups were significant. The minimum $\mathrm{pH}$ value was recorded for Persica at $4.22 \pm 0.03$. The $\mathrm{pH}$ of Matrica was 4.33. Chlorhexidine showed the highest $\mathrm{pH}$ value $(7.3 \pm 0.05)$.

\section{Microhardness}

The microhardness of the acrylic resin specimens was decreased after $12 \mathrm{~h}$ of immersion in all the mouthwashes. There were significant differences between $\mathrm{CHX}$ and Persica, and between $\mathrm{CHX}$ and Matrica in the reduction of microhardness after $12 \mathrm{~h}, 24 \mathrm{~h}$ and 7 days $(\mathrm{p}<0.05)$. Between Persica and Matrica, there were no significant differences in the reduction of hardness in these three time intervals. Reduction in the microhardness of
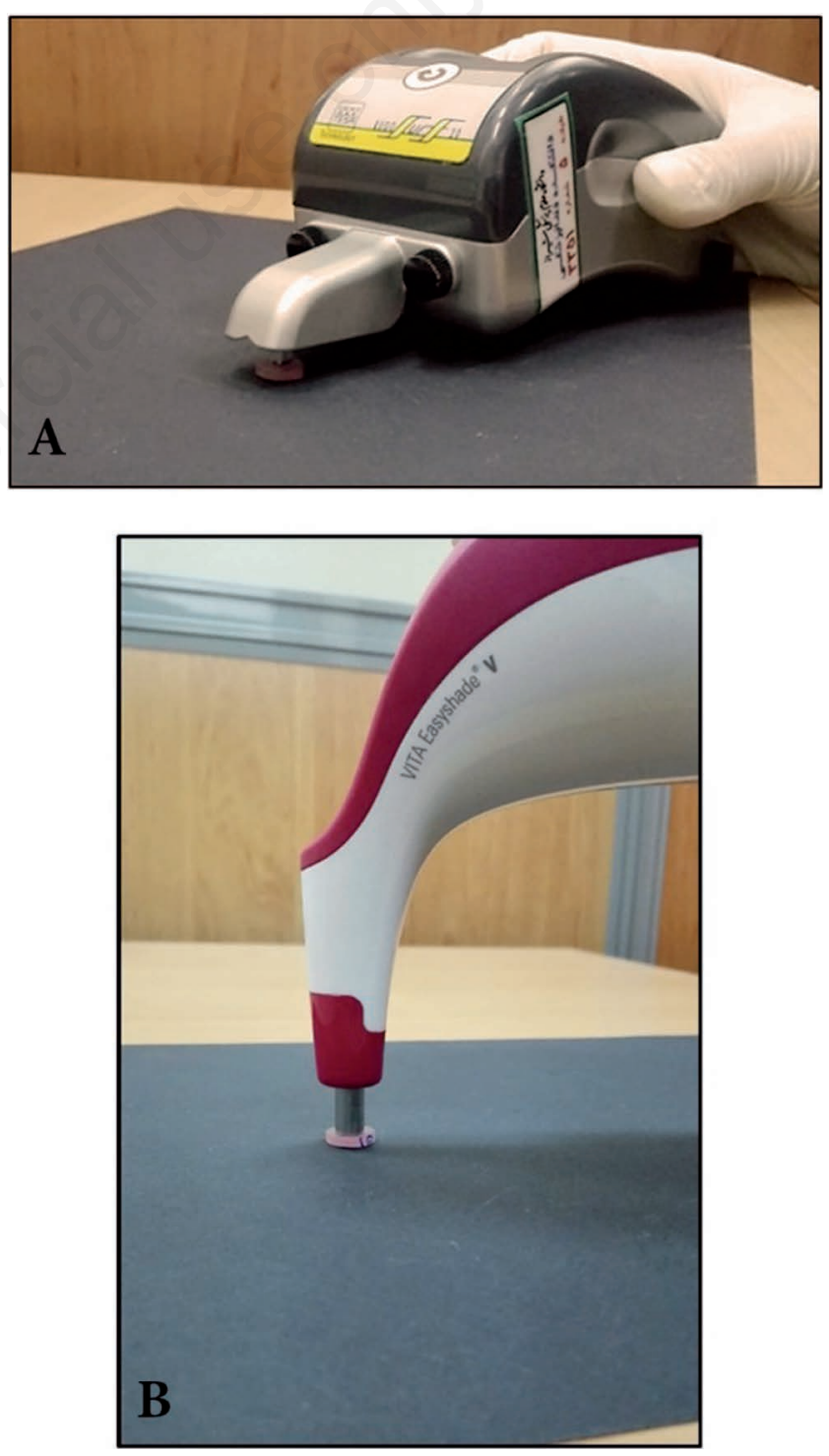

Figure 3. The surface roughness analyzer machine (A) and the spectrophotometer machine (B). 
acrylic resin with herbal mouthwashes was higher than CHX in all the three time periods tested in this study (Table 1).

\section{Roughness}

Surface roughness increased in all tested groups. There was no significant difference between the three types of mouthwash at $12 \mathrm{~h}$ $(\mathrm{P}>0.05)$. Between $\mathrm{CHX}$ and Persica groups there were significant differences in the increase of roughness at $24 \mathrm{~h}(\mathrm{P}<0.05)$. Between $\mathrm{CHX}$ and Matrica groups and between Matrica and Persica groups, the differences in the increase of roughness were negligible at $24 \mathrm{~h}$ $(\mathrm{p}>0.05)$. The differences between CHX, Persica, CHX and Matrica were significant after 7 days $(\mathrm{P}<0.05)$. Between the Persica and Matrica groups, the differences in the increase of roughness were negligible at 7 days $(\mathrm{P}>0.05)$. The increase of surface roughness with the Persica was greater than that of Matrica, but this increase was at its lowest with CHX mouthwashes (Table 2). Table 3 shows the mean value of roughness and Knoop hardness of specimens before and after immersion.

\section{Colorimetric Analysis}

The different mouthwashes in the study showed differences in their colorimetric analysis (using $\Delta \mathrm{E}$ ) after the different time periods used in the test. Between CHX and Persica groups and between CHX and Matrica groups there were significant differences in the increase of color variation at $12 \mathrm{~h}(\mathrm{P}<0.05)$. The differences in the increase of color variation were insignificant between Persica and Matrica groups at $12 \mathrm{~h}(\mathrm{P}>0.05)$. The differences between $\mathrm{CHX}$ and Persica groups in color variation were insignificant at $24 \mathrm{~h}(\mathrm{P}>0.05)$. Between $\mathrm{CHX}$ and Matrica groups and between Persica and Matrica groups there were significant differences in the increase of color variation at $24 \mathrm{~h}(\mathrm{p}<0.05)$. The differences in the increase of color variation after 7 days were significant between all groups $(p<0.05)$ (Table 4$)$.

Table 1. Variation of Knoop hardness values after and before immersion in mouthwashes. (Each two numbers with one common letter in each column, are not significantly different).

\begin{tabular}{lccc} 
Mouthwashes & H (Mean \pm SD $)$ & 7 days \\
CHX & $12 \mathrm{~h}$ & $24 \mathrm{~h}$ & \\
& $0.726 \pm 0.503^{\mathrm{a}}$ & $1.771 \pm 0.248^{\mathrm{a}}$ & $3.244 \pm 0.458^{\mathrm{a}}$ \\
Persica & $1.15 \pm 0.885^{\mathrm{b}}$ & $4.786 \pm 1.311^{\mathrm{b}}$ & $6.556 \pm 0.634^{\mathrm{b}}$ \\
\hline Matrica & $3.284 \pm 0.763^{\mathrm{b}}$ & $4.531 \pm 0.897^{\mathrm{b}}$ & $6.922 \pm 1.004^{\mathrm{b}}$ \\
\hline
\end{tabular}

Table 2. Variation of roughness value, in $\mu \mathrm{m}$, after and before specimen immersion in mouthwashes. (Each two numbers with one common letter in each column, are not significantly different).

\begin{tabular}{lccc} 
Mouthwashes & R (Mean \pm SD $)$ & 7days \\
& $12 \mathrm{~h}$ & $24 \mathrm{~h}$ & \\
CHX & $0.033 \pm 0.024^{\mathrm{a}}$ & $0.21 \pm 0.027^{\mathrm{a}}$ & $0.24 \pm 0.08^{\mathrm{a}}$ \\
Persica & $0.159 \pm 0.104^{\mathrm{a}}$ & $0.397 \pm 0.208^{\mathrm{b}}$ & $0.521 \pm 0.211^{\mathrm{b}}$ \\
\hline Matrica & $0.099 \pm 0.033^{\mathrm{a}}$ & $0.233 \pm 0.072^{\mathrm{ab}}$ & $0.292 \pm 0.061^{\mathrm{b}}$ \\
\hline
\end{tabular}

Table 3. The mean value of roughness and Knoop hardness of specimens before and after immersion.

\begin{tabular}{|c|c|c|c|c|c|c|}
\hline & Ro & ess (Mean & & Knoo & dness (Me & lue) \\
\hline & 12 hours & 24 hours & 7 days & 12 hours & 24 hours & 7 days \\
\hline Mouth washes & $\begin{array}{l}\text { Before } \\
\text { After }\end{array}$ & $\begin{array}{l}\text { Before } \\
\text { After }\end{array}$ & $\begin{array}{l}\text { Before } \\
\text { After }\end{array}$ & $\begin{array}{l}\text { Before } \\
\text { After }\end{array}$ & $\begin{array}{l}\text { Before } \\
\text { After }\end{array}$ & $\begin{array}{c}\text { Before } \\
\text { After }\end{array}$ \\
\hline CHX & $\begin{array}{l}0.847 \\
0.880\end{array}$ & $\begin{array}{l}0.554 \\
0.765\end{array}$ & $\begin{array}{l}0.580 \\
0.822\end{array}$ & $\begin{array}{l}13.246 \\
12.520\end{array}$ & $\begin{array}{l}13.911 \\
12.140\end{array}$ & $\begin{array}{l}14.164 \\
10.919\end{array}$ \\
\hline Persica & $\begin{array}{l}0.837 \\
0.997\end{array}$ & $\begin{array}{l}0.700 \\
1.098\end{array}$ & $\begin{array}{l}0.580 \\
1.101\end{array}$ & $\begin{array}{l}11.382 \\
10.232\end{array}$ & $\begin{array}{c}11.502 \\
6.715\end{array}$ & $\begin{array}{c}11.602 \\
5.045\end{array}$ \\
\hline Matrica & $\begin{array}{l}0.791 \\
0.890\end{array}$ & $\begin{array}{l}0.693 \\
0.927\end{array}$ & $\begin{array}{l}0.762 \\
1.055\end{array}$ & $\begin{array}{l}13.807 \\
10.523\end{array}$ & $\begin{array}{l}11.346 \\
6.815\end{array}$ & $\begin{array}{l}12.628 \\
5.706\end{array}$ \\
\hline
\end{tabular}

Table 4. Variation of color $(\Delta \mathrm{E})$, after and before specimens' immersion in mouthwashes. (Each two numbers with one common letter in each column are not significantly different).

\begin{tabular}{|c|c|c|c|}
\hline Mouthwashes & & $($ Mean \pm SD & \\
\hline & $12 \mathrm{~h}$ & $24 \mathrm{~h}$ & 7 days \\
\hline CHX & $7.891 \pm 0.836$ & $7.310 \pm 2.522$ & $3.240 \pm 1.01$ \\
\hline Persica & $14.790 \pm 1.478$ & $13.539 \pm 1.021$ & $18.452 \pm 0.704$ \\
\hline Matrica & $15.135 \pm 0.609$ & $17.8 \pm 0.21$ & $26.689 \pm 1.839$ \\
\hline
\end{tabular}




\section{Discussion}

In this in vitro study, the effects of the most commonly used chemical mouthwashes (CHX) and two types of herbal mouthwashes (Persica and Matrica) were evaluated on some of the physical properties of self-cured orthodontic acrylic resin. We evaluated the changes in microhardness, roughness and the color of acrylic resin specimens in three time intervals including $12 \mathrm{~h}, 24 \mathrm{~h}$ and 7 days. According to a systematic review done by Mavreas et al. ${ }^{25}$ the mean wearing time of orthodontic removable appliances was $13.4( \pm 10.3)$ months. Patients are usually instructed to immerse their appliances 1 hour a day for disinfection. Accordingly, these three periods of immersion in mouthwashes were defined to simulate the meantime that these appliances may be immersed in mouthwashes during orthodontic treatment. Twelve and $24 \mathrm{~h}$ could replicate the average time of immersion of removable orthodontic appliances used approximately for 1 month during orthodontic treatment. Seven days could replicate the mean immersion time for wearing 6 months of removable appliances. Our null hypothesis was that using the herbal mouthwashes might have a lesser effect on acrylic resin properties since they are alcohol-free, unlike the CHX mouthwash. The other reason why we decided to compare herbal mouthwashes with $\mathrm{CHX}$ was that they had some additional advantages reported in the studies. ${ }^{23,24}$ Most of chemical mouthwashes contain alcohol and fluoride which can be toxic at high dose. Therefore, most herbal mouthwashes are safer in this regard to pregnant women, diabetic patients, and children. Besides in comparison with chemicals, herbal mouthwashes could have additional anti-inflammatory and antioxidant effects, which could be beneficial for gingival health. In several studies it was reported that herbal mouthwashes containing chamomile are more effective against Candida species than CHX. Also, desquamation and irritation of oral mucosal cells are less common with herbal mouthwashes. ${ }^{28}$

The results from the present study indicated that immersion influenced acrylic resin regardless of the type of mouthwash solution used, but this influence was even greater when herbal mouthwashes were used. Therefore, our null hypothesis was rejected. The harder removable appliances are the longer they will resist abrasion, so hardness directly influences their longevity. Decreasing hardness during treatment with removable appliances may make the appliance prone to fracture. ${ }^{29}$ In our study, the microhardness of Acrylic resin was reduced as a result of immersion in all mouthwashes even after $12 \mathrm{~h}$. The effects of herbal mouthwashes on the reduction of microhardness were higher than CHX in the three time intervals. As we mentioned previously, the $\mathrm{pH}$ of herbal mouthwashes used in this study was lower than that of CHX. This acidity might be responsible for the greater softening of acrylic resin. Acid solutions weaken polymer molecule bonds, which makes them softer and more easily degraded. ${ }^{29}$ Jyothi et al. ${ }^{30}$ analyzed the influence of different mouthwashes on the microhardness of restorative materials in an in vitro study. The conclusion of their research was the fact that the lowest $\mathrm{pH}$ in a mouthwash led to the greatest decrease in microhardness. The CHX mouthwash also decreased the microhardness value in our study. The alcohol content of this mouthwash could explain the changes on the acrylic surface. This conclusion supports the former discovery that ethanol softens acrylic resins. ${ }^{12}$ Apparently, both ethanol and water can separate polymer chains from each other by driving them apart and allowing them to slide with greater ease (they will plastically deform). ${ }^{12}$ Ethanol penetrates the matrix and expands the space between the chains ${ }^{31}$, which results in greater plasticization due to lower VHN values for PMMA. ${ }^{32}$ Penugonda et al. ${ }^{33}$ reported that the alcohol in mouthwashes affects the hardness of acrylic resin in the dentures base and that the softening effect is directly related to the percentage of alcohol in the mouthwashes. The surface roughness of acrylic resins is fundamentally important as it directly affects the health of oral tissues in direct contact with the base plate of appliances. ${ }^{34}$ According to Quirynen ${ }^{35}$ and Bollen, ${ }^{36}$ if the base of removable appliances has a rough surface, it accumulates and retains more dental plaque than smooth surfaces. The increased roughness of the surface area may prevent bacteria from being removed either naturally or intentionally using hygiene instructions. Furthermore, Quirynen $^{35}$ and Bollen ${ }^{36}$ demonstrated that bacteria are capable of remaining alive for extended periods when attached to rough surfaces or places that allow them to remain stagnant. According to research, at $0.2 \mathrm{~mm}$ roughness is necessary for the bacteria to be able to remain attached to the surface ${ }^{37}$ In this study, all mouthwashes increased surface roughness more than $0.2 \mathrm{~mm}$, with more increase in herbal mouthwashes than CHX. Persica and Matrica are alcohol-free mouthwashes that have been recently introduced. This increase in surface roughness can be attributed firstly to the low $\mathrm{pH}$ of the mouthwash and secondly to the hygroscopic nature of resin-based materials. ${ }^{38}$ The degradation of the upper layer of acrylic resin has probably been caused by the higher acidity of the mouthwashes in question, which has resulted in greater roughness. When acrylic resin is in contact with the mouthwash for a long period of time, the top layer is removed and a subsurface area is exposed to the mouthwash. This might be the reason for greater roughness when acrylic resin is immersed in Persica and Matrica from $24 \mathrm{~h}$ to 7 days. Similarly, Sadaghiani et al. ${ }^{39}$ did an in vitro study to check the effect of different mouth- rinses on the surface roughness of resin-modified restorative materials and concluded that the mouthwashes with lowest $\mathrm{pH}$ resulted in the greatest increase in the surface roughness. Kamna Gorka in 2016 checked the effect of CHX with herbal mouthwash on the roughness of resin-modified glass ionomer restorative material and concluded that herbal mouthwash increased the roughness of resinbased materials more than $\mathrm{CHX} .{ }^{38} \mathrm{ABO}$ and Yousef did an in vitro study to assess the various restorative materials after exposure to $\mathrm{CHX}$ and concluded that exposure to $\mathrm{CHX}$ for 1 month showed a rise in mean surface roughness values in restorative materials. ${ }^{40}$ The alcohol content of CHX may affect the surface integrity of acrylic resins. Absorption of alcohol molecules into acrylic resin could result in the softening of acrylic resin surface. ${ }^{41}$ This could explain the increased roughness of specimens after immersion in CHX.

Colorimetric analysis using the $\Delta \mathrm{E}$ as a parameter showed that the color of acrylic resin was changed as a result of exposure to different solutions. Persica and Matrica experienced the most noticeable color alteration even after the $12 \mathrm{~h}$ of the immersion period. Acrylic resins may absorb water or aqueous solutions, and pigments dissolved in these solutions may be carried into the body of the resin. ${ }^{42}$ Since the herbal mouthwashes used in this study were darker in comparison to $\mathrm{CHX}$, they caused more color alteration. Factors such as surface roughness, oxidation, dehydration, water absorption, product degradation, and chemical degradation might also contribute to color instability in acrylic resin. ${ }^{43}$ These factors could explain the color changes induced by CHX and herbal mouthwashes.

As patients do not immerse their appliances in mouthwashes for a continuous period of time, the main limitation of our study is the continuous immersion time intervals. This continuity may cause the greater degradation of acrylic resin by ethanol or the 
acidic content of the mouthwashes. Nonetheless, the long period of immersion in this study might be compared to what would actually happen over the course of several months of daily immersion of an acrylic device by the user. To sum up, all mouthwashes used in this study including CHX, Persica, and Matrica had a negative influence on the hardness, roughness and color stability of orthodontic acrylic resin but the effect of herbal mouthwashes on these physical properties was higher than CHX.

\section{References}

1. Littlewood SJ, Tait AG, Mandall NA, et al. The role of removable appliances in contemporary orthodontics. Br Dent $\mathrm{J}$ 2001;191:304-6.

2. Batoni G, Pardini M, Giannotti A, et al. Effect of removable orthodontic appliances on oral colonisation by mutans streptococci in children. Eur J Oral Sci 2001;109:388-92.

3. Pathak AK, Sharma DS. Biofilm associated microorganisms on removable oral orthodontic appliances in children in the mixed dentition. J Clin Pediatr Dent 2013;37:335-9.

4. Glass RT, Conrad RS, Bullard JW, et al. Evaluation of microbial flora found in previously worn prostheses from the Northeast and Southwest regions of the United States. J Prosthet Dent 2010;103:384-9.

5. Lamas R, Salas M, Pereira-Cenci T, et al. Removable orthodontic appliances: Frequency and cleaning agents used by students and recommended by dentists. Braz J Oral Sci 2016;15:21-6.

6. Chauhan P, Dua V, Kainth N, et al. The effect of various oral hygiene products on the microbial flora in patients undergoing orthodontic treatment. APOS Trends Orthod 2015;5:63-9.

7. Mosaddad SA, Tahmasebi E, Yazdanian A, et al. Oral microbial biofilms: an update. Eur J Clin Microbiol Infect Dis 2019;38:2005-19.

8. Salas MMS, Lamas RRS, Cenci TP, et al. How are children and adolescents cleaning their orthodontic appliances? A cross-sectional study in private schools. Braz J Oral Sci 2014;13:34-6.

9. Peixoto IT, Enoki C, Ito IY, et al. Evaluation of home disinfection protocols for acrylic baseplates of removable orthodontic appliances: A randomized clinical investigation. Am J Orthod Dentofacial Orthop 2011;140:51-7.

10. Lee HH, Lee CJ, Asaoka K. Correlation in the mechanical properties of acrylic denture base resins. Dent Mater J 2012;31:157-64.

11. Ferracane JL. Hygroscopic and hydrolytic effects in dental polymer networks. Dent Mater J 2006;22:211-22.

12. Pavarina AC, Machado AL, Giampaolo ET, et al. Effects of chemical disinfectants on the transverse strength of denture base acrylic resins. J Oral Rehabil 2003;30:1085-9.

13. Fernandes FH, Orsi IA, Villabona CA. Effects of the peracetic acid and sodium hypochlorite on the colour stability and surface roughness of the denture base acrylic resins polymerised by microwave and water bath methods. Gerodontol 2013;30:18-25.

14. Miranda Dde A, Bertoldo CE, Aguiar FH, et al. Effects of mouthwashes on Knoop hardness and surface roughness of dental composites after different immersion times. Braz Oral Res 2011;25:168-73.

15. Khalessi AM, Pack AR, Thomson WM, et al. An in vivo study of the plaque control efficacy of Persica: a commercially available herbal mouthwash containing extracts of Salvadora persica. Int Dent J 2004;54:279-83.
16. Seifi Kafshgari H, Yazdanian M, Ranjbar, R, et al. The effect of Citrullus colocynthis extracts on Streptococcus mutans, Candida albicans, normal gingival fibroblast and breast cancer cells. J Biol Res 2019;92:30-3.

17. Khojaste M, Yazdanian M, Tahmasebi E, et al. Cell Toxicity and inhibitory effects of Cyperus rotundus extract on Streptococcus mutans, Aggregatibacter actinomycetemcomitans and Candida albicans. Eur J Transl Myol 2018;28:362-9

18. Rezaeeyan Z, Safarpour A, Amoozegar MA, et al. High carotenoid production by a halotolerant bacterium, Kocuria sp. Strain QWT-12 and anticancer activity of its carotenoid. EXCLI J 2017;16:840-51.

19. Khan M, Alkhathlan HZ, Khan ST. Antibiotic and Antibiofilm Activities of Salvadora persica L. Essential Oils against Streptococcus mutans: A Detailed Comparative Study with Chlorhexidine Digluconate. Pathogens 2020;9:66.

20. Fernandes AU, Goiato MC, Batista MA, et al. Color alteration of the paint used for iris painting in ocular prostheses. Braz Oral Res 2009;23:386-92.

21. Tahmasebi E, Alikhani M, Yazdanian A, et al. The current markers of cancer stem cell in oral cancers. Life Sci 2020;249:117483.

22. Khomarlou N, Aberoomand-Azar P, Lashgari AP, et al. Essential oil composition and in vitro antibacterial activity of Chenopodium album subsp. striatum. Acta Biol Hung 2018;69:144-55.

23. Cai H, Chen J, Panagodage Perera NK, et al. Effects of Herbal Mouthwashes on Plaque and Inflammation Control for Patients with Gingivitis: A Systematic Review and Meta-Analysis of Randomised Controlled Trials. Evid Based Complement Alternat Med 2020;2020:1-16.

24. Manipal S, Hussain S, Wadgave U, et al. The mouthwash warchlorhexidine vs. herbal mouth rinses: A meta-analysis. J Clin Diagn Res 2016;10:ZC81-3.

25. Mavreas D, Athanasiou AE. Factors affecting the duration of orthodontic treatment: a systematic review. Eur J Orthod 2008;30:386-95.

26. Heidari MF, Arab SS, Noroozi-Aghideh A, et al. Evaluation of the substitutions in 212, 342 and 215 amino acid positions in binding site of organophosphorus acid anhydrolase using the molecular docking and laboratory analysis. Bratisl Lek Listy 2019;120:139-43.

27. Taherian A, Fazilati M, Moghadam AT, et al. Optimization of purification procedure for horse $\mathrm{F}\left(\mathrm{ab}^{\prime}\right) 2$ antivenom against Androctonus crassicauda (Scorpion) venom. Trop J Pharm Res 2018;17:409-14.

28. Parwani SR, Parwani RN, Chitnis PJ, et al. Comparative evaluation of anti-plaque efficacy of herbal and $0.2 \%$ chlorhexidine gluconate mouthwash in a 4-day plaque re-growth study. J Indian Soc Periodontol 2013;17:72-77.

29. Goiato MC, Dos Santos DM, Andreotti AM, et al. Effect of beverages and mouthwashes on the hardness of polymers used in intraoral prostheses. J Prosthodont 2014;23:559-64.

30. Jyothi K, Crasta S, Venugopal P. Effect of five commercial mouth rinses on the microhardness of a nanofilled resin composite restorative material: An in vitro study. J Conserv Dent 2012;15:214-7.

31. Polydorou O, Trittler R, Hellwig E, et al. Elution of monomers from two conventional dental composite materials. Dent Mater J 2007;23:1535-41.

32. Łagocka R, Mazurek-Mochol M, Jakubowska K, et al. Analysis of Base Monomer Elution from 3 Flowable Bulk-Fill Composite Resins Using High Performance Liquid 
Chromatography (HPLC). Med Sci Monit 2018;24:4679-90.

33. Penugonda B, Settembrini L, Scherer W, et al. Alcohol-containing mouthwashes: effect on composite hardness. J Clin Dent 1994;5:60-2.

34. Al-Rifaiy MQ. The effect of mechanical and chemical polishing techniques on the surface roughness of denture base acrylic resins. Saudi Dent J 2010;22:13-7.

35. Quirynen M, Marechal M, Busscher HJ, et al. The influence of surface free energy and surface roughness on early plaque formation. An in vivo study in man. J Clin Periodontol 1990;17:138-44.

36. Bollen CM, Lambrechts P, Quirynen M. Comparison of surface roughness of oral hard materials to the threshold surface roughness for bacterial plaque retention: a review of the literature. Dent Mater J 1997;13:258-69.

37. Collares F, Rostirolla F, Macedo E, et al. Influence of mouthwashes on the physical properties of orthodontic acrylic resin. Braz J Oral Sci 2014; 13:203-8.

38. Gorka K, Kamal V, Kumar A, et al. Comparative Evaluation of
Erosive Potential of a Chemical and Herbal Mouthwash on the Surface Roughness of Resin-modified Glass Ionomer Restorative Materials: An in vitro Study. Int J Prev Clin Dent Res 2016;3:30-4.

39. Sadaghiani L, Wilson MA, Wilson NH. Effect of selected mouthwashes on the surface roughness of resin modified glassionomer restorative materials. Dent Mater J 2007;23:325-34.

40. NAGA AE, M Y. Evaluation of Different Restorative Materials after Exposure to Chlorhexidine. J Am Sci 2012;8:628-31.

41. Porto I, Le D, Ck D, et al. A Comparative Effect of Mouthwashes with Different Alcohol Concentrations on Surface Hardness, Sorption and Solubility of Composite Resins. Oral Health Dent Manag 2014;13:502-6.

42. Goiato MC, Nobrega AS, dos Santos DM, et al. Effect of different solutions on color stability of acrylic resin-based dentures. Braz Oral Res 2014;28:1-7.

43. Leite VM, Pisani MX, Paranhos HF, et al. Effect of ageing and immersion in different beverages on properties of denture lining materials. J Appl Oral Sci 2010;18:372-8. 